\title{
Comparative Study of Some Heavy and Trace Metals in Selected Vegetables from four Local Government Areas of Plateau State, Nigeria
}

\author{
*Dabak Jonathan Dingkwoet, Solomon Mariam Danladi and \\ Mafulul Simon Gabriel \\ Department of Biochemistry, College of Medical Sciences, University of Jos, P.M.B. 2084, Jos, Nigeria
}

\begin{abstract}
This study was conducted to analyze some heavy and trace metal contents of selected edible vegetables commonly sold in four local government areas (LGAs) of Plateau State, Nigeria, with a view to unearth their toxicological implications on the populace. The vegetables sampled are Spinacia oleracea (spinach), Lactuca sati (lettuce), Cucumis sativus (cucumber), Daucus car (carrot) and Brassica oleracea (cabbage), while the metals analysed are $\mathrm{Cd}, \mathrm{Pb}, \mathrm{Fe}, \mathrm{Cr}$ and $\mathrm{Mn}$. Atomic absorption spectrophotometer was used to determine the concentration of the various metals and Tukey-Kramer multiple comparison tests in a one-way analysis of variance was used to compare variations in metal concentrations. $\mathrm{Cd}$ and $\mathrm{Pb}$ were not detected in all the vegetables sampled from Bassa LGA, but were detected in vegetables of Jos-North, Jos-South and Barkin Ladi LGAs. Cd and Pb concentrations in most samples from Jos-North, Jos-South and Barkin Ladi LGAs were above the WHO maximum permissible limits for vegetables. Cr concentrations in all the vegetables from all the LGAs were far above the WHO maximum permissible limit in the order: Jos-South > Jos-North > Barkin Ladi > Bassa. Fe concentration in most vegetables from all the LGAs is above the WHO maximum permissible limit in the orders: Jos-North - Lettuce $>$ Spinach $>$ cucumber $>$ carrot $>$ cabbage; Jos-South Lettuce $>$ Spinach $>$ cabbage $>$ carrot $>$ cucumber; Barkin Ladi - Lettuce $>$ cucumber $>$ Spinach $>$ carrot $>$ cabbage; Bassa - Letuce $>$ carrot $>$ spinach $>$ cabbage $>$ cucumber. Mn order of concentrations in the vegetables is: Jos-north - spinach > Lettuce > carrot > cucumber > cabbage; Jos-South - spinach > lettuce > cabbage $>$ carrot $>$ cucumber; Barkin Ladi - Lettuce $>$ cucumber $>$ Spinach $>$ carrot $>$ cabbage; Bassa Lettuce $>$ spinach $>$ cabbage $>$ carrot $>$ cucumber. The order of lead concentrations in the vegetables are: JosNorth - cabbage $>$ spinach $>$ carrot $>$ lettuce $>$ cucumber; Jos-South - Lettuce $>$ cucumber $>$ carrot $>$ cabbage $>$ spinach; Barkin Ladi - Lettuce $>$ spinach $>$ cucumber $>$ carrot $>$ cabbage. The results indicate that vegetables from Jos-North, Jos-South and Barkin Ladi are contaminated with the metals sampled, while lettuce and spinach are very good bioaccumulators of these metals.
\end{abstract}

Keywords: Comparative, Heavy metals, Trace Metals, Vegetables, contamination, bioaccumulation

\section{Introduction}

Living organisms require varying amounts of some metals such as iron, manganese, chromium, cobalt, copper, and zinc. Excessive levels of these metals can be damaging to humans and other animals. Other metals such as mercury, cadmium and lead are toxic, have no known beneficial role in an organism and their accumulation over time in the bodies of animals can cause serious health problems [1,2]. Toxicity of these nonessential metals occurs through the displacement of essential metals from their native binding sites [3,4], or through ligand interaction [5]. In addition, at high levels of both essential and non-essential metals, they can damage cell membranes, alter enzyme specificity, disrupt cellular functions and damage the structure of DNA [6].

Mineral rock weathering and anthropogenic sources provide these two types of metals in the soil. The anthropogenic sources of the metal contamination include metalliferous mining and smelting, industrial waste dumps, atmospheric deposition, agricultural processes and waste disposal from treatment plants [7]. The excessive addition of nitrogen and other inorganic fertilizers and organic manures to vegetables can accumulate high levels of nitrates and other anions as well as heavy metals $[8,9,10]$.

Leafy vegetables occupy a very important place in the human diet, but unfortunately, constitute a group of foods which contributes maximally to nitrate and other anions as well as heavy metals consumption. Consequently, their consumption by humans and animals can pose serious health hazards if contaminated with heavy metals. Although some heavy metals such as copper, zinc, manganese, and iron are essential in plant nutrition, many of them do not play any significant role in the plant physiology. The uptake of these metals by plants especially the leafy vegetables is an avenue of their entry into the human food chain with its attendant harmful effects on health $[11,12]$. 
With the increased knowledge that vegetables play a special role in human nutrition, especially as sources of vitamins, minerals and dietary fibers, proteins and essential fatty acids, people in the study areas have shown increased interest in its consumption. However, these heavy and essential trace metals are given special attention throughout the world due to their toxic effect in the body when their concentrations exceed limits of safe exposure [13]. The concentrations of these metals in vegetables may vary depending on the inherent and environmental conditions of plants. Contamination with these metals is a serious threat because of their toxicity, bioaccumulation and biomagnifications in the food chain. Survey of the literature indicates that studies related to the determination of heavy and trace metal levels in different vegetables in the study areas are scarce. Therefore, this work seeks to determine the concentrations of some metals in vegetables commonly sold in markets of the study areas, and to compare their concentrations with the WHO maximum permissible limits in vegetables.

\subsection{Study Locations}

\section{Materials And Methods}

The study areas are Bassa, Jos-North, Jos-South and Barkin Ladi Local Government Areas (LGAs) of Plateau State, Nigeria. These areas were chosen because large-scale mining activities were carried out in these areas except Bassa, leaving behind mining taillings which dry-season farmers use as sources of water for irrigation. Also, in Jos-North and Jos-South LGAs, industrial waste water are channeled into the streams that are used as irrigation water in some locations. The vegetables produced from these irrigation activities are mainly sold to residents of Jos-Bukuru metropolis of the study areas. Very little mining was carried out in Bassa LGA and there are no industries also.

\subsection{Sample Collection}

Vegetables used in the study are Spinacia oleracea (spinach), Lactuca sati (lettuce), Cucumis sativus (cucumber), Daucus car (carrot) and Brassica oleracea (cabbage), which are commonly sold in the local markets in the study areas. These vegetables were collected during the peak period of their harvest. The different vegetables were randomly collected from three farms within each LGA. Samples of the vegetables collected were wrapped in black polythene bags, properly labeled and immediately taken to the laboratory for processing and analysis. Each sample was removed from its bag, washed with tap water to remove any soil particles and rinsed with distilled water. The edible parts of the vegetable samples were air-dried in the laboratory for twentyfour hours to reduce the water content after which all the samples were oven-dried at $70^{\circ} \mathrm{C}$ for 24 hours. The dried samples were then powdered using a Teflon pestle and mortar, sieved with muslin cloth and stored in airtight containers until required for digestion.

\subsection{Digestion of Samples}

For each vegetable sample, three powdered samples from each sampling area (1g each) were accurately weighed and placed in crucibles, three replicates for each sample. Each sample was digested using the combination of nitric acid, perchloric acid and hydrochloric acid in the ratio of 1:6:1. The digested samples were dissolved with $2 \mathrm{ml}$ of nitric acid for $10 \mathrm{~min}$, removed and allowed to cool and then transferred into $100 \mathrm{ml}$ volumetric flask and made up to the mark with distilled water.

\subsection{Analysis}

The samples were analysed for $\mathrm{Cd}, \mathrm{Pb}, \mathrm{Fe}, \mathrm{Mn}$ and $\mathrm{Cr}$ using the Inductive Coupled Plasma Emission Spectrophotometer (ICP-AES 2000DV), at the Department of Geology and Mining, University of Jos. All reagents used were of analytical grade obtained from the Department of Biochemistry, University of Jos. Analysis was carried out in duplicates and the mean values \pm standard deviations were automatically calculated by the spectrophotometer.

\section{Results}

\subsection{Concentrations of some heavy metals in the vegetables obtained from Jos-North LGA}

Table 1 shows the concentrations of cadmium, chromium, iron, manganese and lead in the various vegetables sampled from Jos-North LGA. Cadmium was not detected in lettuce and cucumber but was present in high concentrations in cabbage, carrot and spinach; the highest concentration being in cabbage. Cabbage also has the highest concentration of chromium and lead but low in iron and manganese. Lettuce has the highest concentration of iron while spinach has the highest concentration of manganese.

\subsection{Concentrations of some heavy metals in the vegetables obtained from Jos-South LGA}

Table 2 shows the concentrations of the various metals in the vegetables sampled from Jos-South LGA. Cadmium was found to be present in all the vegetables except lettuce. Spinach has the highest concentration of 
cadmium. Lead is present in all the vegetables sampled from Jos-South LGA with lettuce having the highest concentration. Lettuce also has the highest concentration of iron, while spinach and cabbage have the highest concentrations of manganese and chromium respectively.

\subsection{Concentrations of some heavy metals in the vegetables obtained from Bassa LGA}

Table 3 shows the concentrations of the different metals in the various vegetables sampled in Bassa LGA. Cadmium and lead were not detected in all the vegetables sampled. Lettuce has the highest concentrations of chromium, iron and manganese, while cucumber has the least of all these metals.

\subsection{Concentrations of some heavy metals in the vegetables obtained from Barkin-Ladi LGA}

Table 4 shows the concentrations of the different metals in the various vegetables sampled in Barkin Ladi LGA. Cadmium and lead were detected in all the vegetables sampled in this LGA, with lettuce having the highest concentration of each of the sampled metals. Iron was not detected in cabbage and carrot. The concentrations of chromium, iron and manganese are generally lower than what was obtained from other LGAs.

\subsection{Comparative concentration of cadmium in the various vegetables from the different LGAs}

Fig. 1 shows the distribution of cadmium in the various vegetables from the different LGAs. Cabbage from Jos-North has the highest concentration followed by spinach from Jos-South LGA. Carrot and cucumber from Jos-South have significant concentration of the metal, while all the vegetables from Barkin Ladi contain the metal. The metal was not detected in all the vegetables from Bassa LGA.

\subsection{Comparative concentration of chromium in the various vegetables from the different LGAs}

Fig. 2 shows the concentrations of chromium in the different vegetables from all the LGAs. From the result, chromium is found in all the vegetables from all the LGAs with Jos-South having the highest concentration of the metal in all the vegetables, followed by Jos-North, Barkin Ladi and Bassa respectively.

\subsection{Comparative concentration of iron in the various vegetables from the different LGAs}

Fig. 3 shows the concentrations of iron in the different vegetables from all the LGAs. Iron is present in all the vegetables from all the LGAs with lettuce having the highest concentration of the metal from all the LGAs. Lettuce from Jos-South has the highest concentration of the metal, followed by Bassa and Jos-North respectively. Barkin Ladi has the least concentration of the metal in all the vegetables.

\subsection{Comparative concentration of manganese in the various vegetables from the different LGAs}

Fig. 4 shows concentrations of manganese in the various vegetables from all the LGAs. Bassa has the highest concentration of metal in cabbage and carrot followed by Jos-South and Jos-North respectively. In cucumber, Jos-North has the highest followed by Jos-South, Bassa and Barkin Ladi respectively. Jos-South has the highest followed by Bassa, Jos-North and Barkin Ladi respectively. Jos-South still has the highest in spinach followed by Jos-North, Bassa and Barkin Ladi in that order. It is observed that Barkin Ladi has the lowest concentration of the metal in all the vegetables.

\subsection{Comparative concentration of lead in the various vegetables from the different LGAs}

Fig. 5 shows the concentrations of lead in the various vegetables sampled from all the LGAs. All the vegetables from Jos-North and Jos-South have very high concentrations of the metal; Barkin Ladi has a significant concentration of the metal in all the vegetables except cabbage. The metal was not detected in all the vegetables sampled from Bassa LGA.

Table 1: Concentrations of some heavy metals in $\mathrm{mg} / \mathrm{Kg}$ in the vegetables obtained from Jos-North

\begin{tabular}{lllllll}
\hline \multicolumn{7}{c}{ LGA. } \\
\hline S/No & Vegetables & {$[\mathbf{C d}]$} & {$[\mathbf{C r}]$} & {$[\mathbf{F e}]$} & {$[\mathbf{M n}]$} & {$[\mathbf{P b}]$} \\
\hline 1. & Cabbage & $6.168 \pm 0.02$ & $16.28 \pm 0.27$ & $310.50 \pm 0.45$ & $25.45 \pm 0.47$ & $22.76 \pm 0.54$ \\
2. & Carrot & $0.729 \pm 0.04$ & $12.02 \pm 1.02$ & $584.90 \pm 0.40$ & $37.81 \pm 1.01$ & $19.02 \pm 0.28$ \\
3. & Cucumber & ND & $11.07 \pm 0.08$ & $713.60 \pm 2.10$ & $25.77 \pm 1.08$ & $10.53 \pm 0.53$ \\
4. & Lettuce & ND & $11.45 \pm 0.69$ & $1950.00 \pm 1.00$ & $66.88 \pm 0.91$ & $15.87 \pm 0.08$ \\
5. & Spinach & $0.145 \pm 0.06$ & $12.96 \pm 0.14$ & $874.90 \pm 0.36$ & $293.00 \pm 0.36$ & $20.98 \pm 1.01$ \\
6. & *WHO MPL & 0.1 & 0.05 & 425 & $* *$ NA & 0.3 \\
\hline
\end{tabular}

ND - Not detected

*WHO MPL = World Health Organisation Maximum Permissible limit.

**Not available 
Comparative Study of Some Heavy and Trace Metals in Selected Vegetables from four Local

Table 2: Concentrations of some heavy metals in $\mathrm{mg} / \mathrm{Kg}$ in the vegetables obtained from Jos-South LGA

\begin{tabular}{|c|c|c|c|c|c|c|}
\hline S/No & Vegetables & {$[\mathrm{Cd}]$} & {$[\mathrm{Cr}]$} & {$[\mathrm{Fe}]$} & [Mn] & {$[\mathrm{Pb}]$} \\
\hline 1. & Cabbage & $0.039 \pm 0.02$ & $53.80 \pm 0.21$ & $1072.00 \pm 2.10$ & $73.88 \pm 0.01$ & $11.26 \pm 0.14$ \\
\hline 2. & Carrot & $0.181 \pm 0.01$ & $16.39 \pm 0.20$ & $690.40 \pm 0.28$ & $47.97 \pm 0.02$ & $16.15 \pm 0.03$ \\
\hline 3. & Cucumber & $0.197 \pm 0.01$ & $24.78 \pm 0.39$ & $520.70 \pm 0.49$ & $22.52 \pm 0.04$ & $21.94 \pm 0.02$ \\
\hline 4. & Lettuce & ND & $42.07 \pm 0.01$ & $16350.00 \pm 3.53$ & $457.70 \pm 0.14$ & $22.66 \pm 0.07$ \\
\hline 5. & Spinach & $0.542 \pm 0.01$ & $18.96 \pm 0.04$ & $1094.00 \pm 1.41$ & $542.00 \pm 1.41$ & $10.99 \pm 0.02$ \\
\hline 6. & WHO MPL & 0.1 & 0.05 & 425 & NA & 0.3 \\
\hline
\end{tabular}

Table 3: The concentrations of some heavy metals in $\mathrm{mg} / \mathrm{Kg}$ in the vegetables obtained from Bassa

\begin{tabular}{lllllll}
\hline S/No & Vegetables & {$[\mathbf{C d}]$} & {$[\mathbf{C r}]$} & {$[\mathbf{F e}]$} & {$[\mathbf{M n}]$} & LGA. \\
\hline 1. & Cabbage & ND & $5.531 \pm 0.02$ & $680.80 \pm 1.00$ & $112.70 \pm 0.11$ & ND \\
2. & Carrot & ND & $5.011 \pm 0.15$ & $980.90 \pm 0.22$ & $53.71 \pm 0.94$ & ND \\
3. & Cucumber & ND & $4.109 \pm 0.55$ & $350.10 \pm 0.45$ & $20.84 \pm 0.19$ & ND \\
4. & Lettuce & ND & $20.400 \pm 0.99$ & $5335.00 \pm 3.50$ & $150.80 \pm 0.22$ \\
5. & Spinach & ND & $6.358 \pm 0.10$ & $740.20 \pm 0.01$ & $147.40 \pm 0.09$ & ND \\
6. & WHO MPL & 0.1 & 0.05 & 425 & & NA \\
\hline
\end{tabular}

Table 4: The concentrations of some heavy metals in $\mathrm{mg} / \mathrm{Kg}$ in the vegetables obtained from Barkin-

\begin{tabular}{lllllll}
\hline \multicolumn{7}{c}{ Ladi LGA. } \\
\hline S/No & Vegetables & {$[\mathbf{C d}]$} & {$[\mathbf{C r}]$} & {$[\mathbf{F e}]$} & {$[\mathbf{M n}]$} & {$[\mathbf{P b}]$} \\
\hline 1. & Cabbage & $0.102 \pm 0.02$ & $8.770 \pm 0.20$ & ND & $4.182 \pm 0.41$ & $0.114 \pm 0.56$ \\
2. & Carrot & $0.092 \pm 0.01$ & $13.320 \pm 1.84$ & ND & $4.900 \pm 0.24$ & $1.251 \pm 0.05$ \\
3. & Cucumber & $0.089 \pm 0.11$ & $8.944 \pm 0.35$ & $84.50 \pm 0.25$ & $9.544 \pm 0.19$ & $1.762 \pm 0.18$ \\
4. & Lettuce & $0.140 \pm 0.01$ & $8.709 \pm 0.23$ & $87.20 \pm 0.50$ & $10.800 \pm 0.22$ & $2.423 \pm 0.02$ \\
5. & Spinach & $0.124 \pm 0.20$ & $6.849 \pm 1.06$ & $45.00 \pm 0.01$ & $7.591 \pm 0.09$ & $1.933 \pm 0.25$ \\
6. & WHO MPL & 0.1 & 0.05 & 425 & NA & 0.3 \\
\hline
\end{tabular}
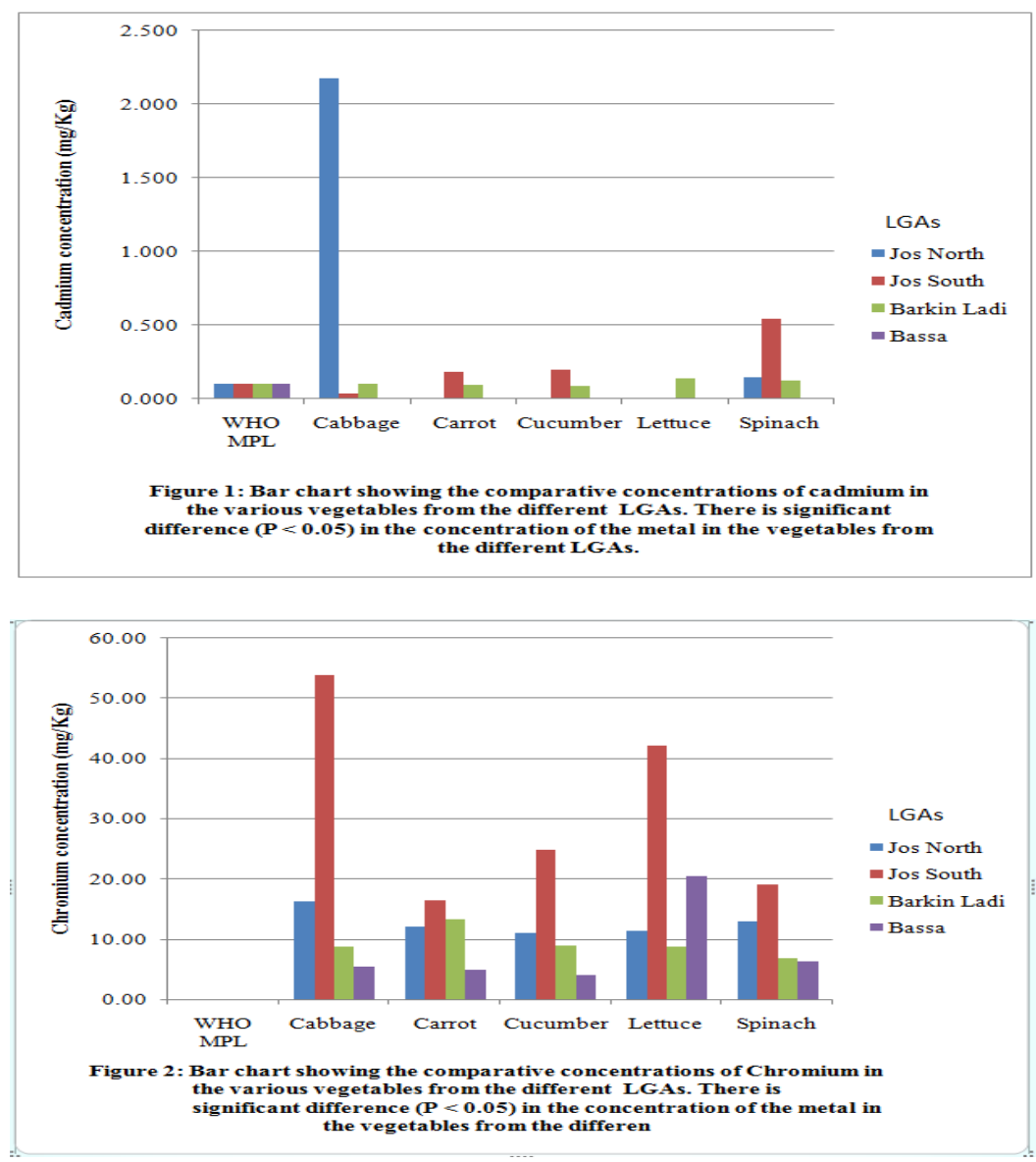

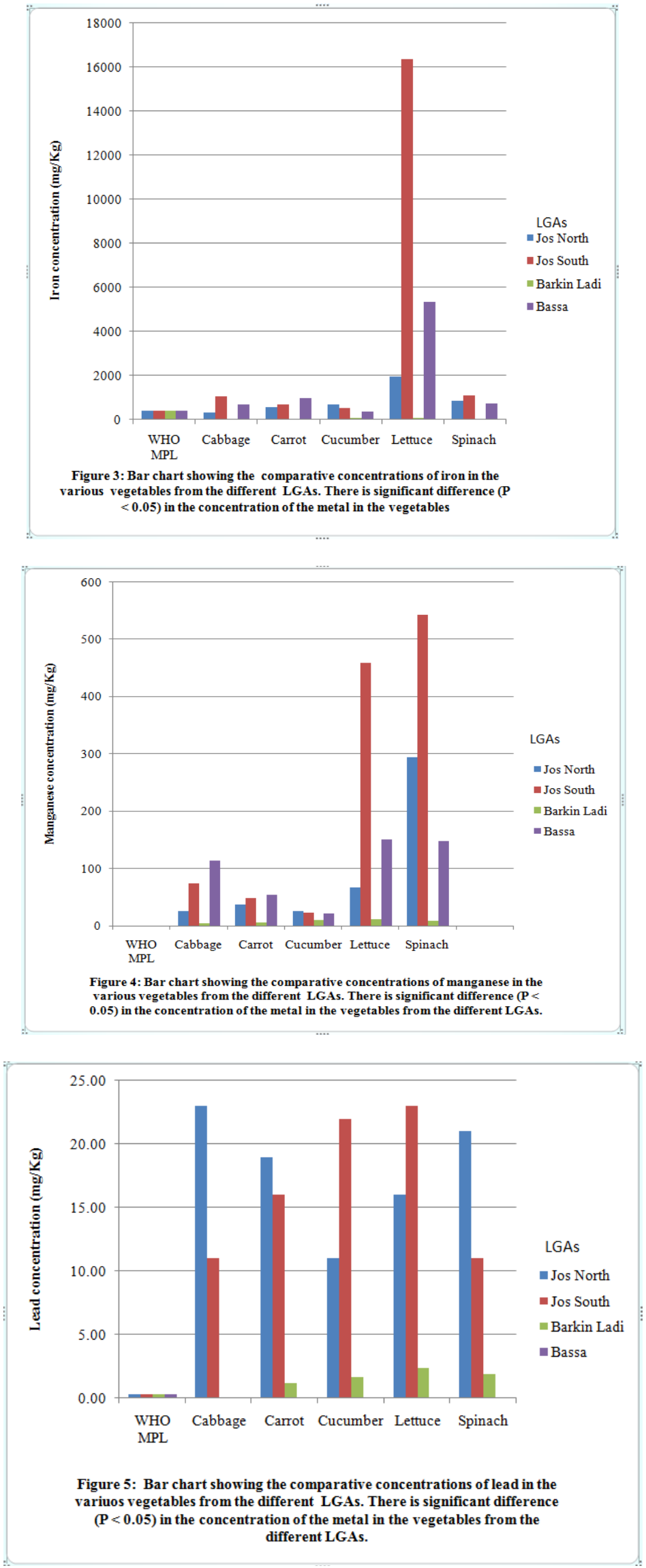


\section{Discussion}

Vegetables from Jos-North LGA (table 1) are contaminated with the metals analysed with concentrations far above the WHO maximum permissible limits. This may be attributed to anthropogenic activities as mining tailings are scattered in this area, increased industrialization, industrial wastes, and automobiles and their attendant bye products which may be released into the environment. When these metals find their ways into the soil or water bodies that may be eventually used for agricultural purposes, this can pose a big hazard to humans via the food chain as demonstrated by Arora et al [14], Asdeo and Loonker [15], and Khan et al [16]. They showed that the application of wastewater generally led to changes in the physicochemical characteristics of soil and consequently heavy metal uptake by vegetables. It was clearly observed that the concentration of all the heavy metals were higher in wastewater-irrigated vegetables than freshwater-irrigated plants.

The vegetables from Jos-South LGA (table 2) are contaminated with all the metals analysed. However, cadmium was not detected in lettuce; cabbage concentration is below the WHO maximum permissible limit in the vegetables. Jos-South is home to many industries and mining tailings, and had witnessed increase in automobiles also. These may be the contributory factors that led to this level of contamination. Lead concentration ranges from $10.99 \pm 0.02$ to $22.66 \pm 0.07 \mathrm{mg} / \mathrm{Kg}$ in all the vegetables sampled. This is far above the WHO maximum permissible limit of $0.3 \mathrm{mg} / \mathrm{Kg}$ in vegetables. Similar results were obtained by Kim et al [17] from a mine site in Korea; Khan et al [16] in tomato irrigated with waste water in Pakistan; Tsafe et al [18], Audu and Lawal [19], Lawal and Audu [20] in vegetables in northern Nigeria. The uptake of lead in plants is also regulated by $\mathrm{pH}$, particle size and Cat-ion exchange capacity of soil as well as by root exudation and other physico-chemical parameters [21]. The results obtained are also similar with that of Singh et al [22] and that of Ramesh and Yogananda Murthy [23], who found the presence of lead in leafy vegetables examined above the WHO maximum permissible limit. The introduction of lead into the food chain at high concentration may affect human health and thus, studies concerning lead accumulation in vegetables have increasing importance, so also cadmium, so that alarm can be raised to save the populace from toxicity. Cadmium concentration is highest in cabbage which is in agreement with the work of Asdeo and Loonker [15].

The vegetables from Bassa LGA are not contaminated with the heavy metals cadmium and lead, but contain the essential trace metals chromium, iron and manganese in concentrations higher than the WHO permissible limits in vegetables, but lower than those of Jos-North and Jos-South LGAs (table 3). This may be due to the fact that Bassa LGA is a semi-urban area which has no industries, reduced presence of automobiles and there are no mining tailings as compared to Jos-North and Jos-South LGAs. This observation further gives credence to the fact that industrialization [6,15,24, 25]; automobiles [26] and mining tailings [27] constitute a threat to the food chain.

The vegetables from Barkin Ladi show that they all contain cadmium but cabbage and carrot have concentrations that are lower than the WHO maximum permissible limits in vegetables, while cucumber has the concentration that is not significantly different from the WHO maximum permissible limit $(\mathrm{P}>0.05)$. Lettuce and spinach have cadmium concentration that is above WHO-MPL and is significantly different $(\mathrm{P}>0.05)$. All the vegetables contain lead concentrations that are significantly different $(\mathrm{P}>0.05)$ from each other. Iron concentrations in all the vegetables are below the WHO-MPL (table 4). These results go to show that the contamination of the vegetables from Barkin Ladi may be as a result of the mining tailings only as the extent of contamination is not as high as for Jos-North and Jos-South.

Cadmium is found to contaminate all vegetables from Jos-South and Barkin Ladi, while only cabbage and spinach are affected in Jos-North (Fig.1). Spinach and cabbage appear to be better bioaccumulators of this metal and hence can be sources of cadmium toxicity when they are cultivated on contaminated soil or irrigated with contaminated water. Long-term high cadmium exposure may cause skeletal damage, first reported from Japan, where the itai-itai (ouch-ouch) disease (a combination of osteomalacia and osteoporosis) was discovered in the 1950s. The exposure was caused by cadmium-contaminated water used for irrigation of local rice fields. A few studies outside Japan have reported similar findings [28]. During recent years, new data have emerged suggesting that relatively low cadmium exposure may also give rise to skeletal damage, evidenced by low bone mineral density (osteoporosis) and fractures, renal failure and cancer [4, 29, 30].

All the vegetables from our results can bioaccumulate chromium very efficiently and therefore all can be good sources of the metal (Fig.2). When these vegetables are grown in contaminated soil or irrigated with contaminated water as is the case in our study, they can be very good sources of chromium toxicity. Exposure to chromium may occur through eating these vegetables. In human beings and animals, it is considered to be an essential metal for carbohydrates and lipid metabolism within a certain range of concentrations (up to $200 \mu \mathrm{g} / \mathrm{day})$. However, exceeding normal concentrations leads to accumulation and toxicity that can result to hepatitis, gastritis, ulcers and lung cancer [31]. Jos-South is having the highest concentration of the metal in all the vegetables. This suggests that chromium pollution is highest in the LGA.

Lettuce and spinach are very efficient bioaccumulators of iron as the concentration of the metal in all the LGAs are higher than the rest of the vegetables (Fig.4). Good sources of iron could be from lettuce and 
spinach but they can also be sources of iron over-load when they are planted on contaminated soils or irrigated with contaminated water and hence iron toxicity. Iron in the body is found in haemoglobin, myoglobin, ferritin, haemosiderin, transferrin and enzymes like cytochromes. Excessive binding of iron causes denaturation of ferritin molecule which undergoes aggregation, to form haemosiderin. Mobilization of iron from haemosiderin is very slow. Thus there is accumulation of haemosiderin leading to the condition called haemosiderosis. Massive deposits of haemosiderin in tissues lead to haemachromatosis. If this takes place in the liver, it causes cirrhosis. In pancreas, it damages $\beta$ cells which results in Bronze diabetes. The skin of the patient has bronze coloration. Oxidative damage to cardiac muscle is said to be the biggest health concern [32].

Lettuce and spinach are also very good bioaccumulators of manganese as they have shown the capacity to bioaccumulate the metal more than the other vegetables in all the LGAs (Fig.4). This goes to confirm the fact that lettuce and spinach are among the excellent food sources of manganese. Others include kidney, muscle meats, tea, legumes, nuts and whole-grain breads and cereals [33]. However, when grown on contaminated soil or water, they can pose a health risk as a result of manganese toxicity. Manganese plays a role in bone formation and in the metabolism of protein, carbohydrate and fat. Acute poisoning leads to fever or manganese pneumonitis and liver damage, while chronic and long-term effects lead to neurotoxicity. Infants, children and menstruating women are at greater risk due to greater transport into the central nervous system and greater retention of manganese in the brain leading to stillbirths and birth defects [33].

All the vegetables from this study are good bioaccumulators of lead (Fig.5). Lead pollution is greatest in vegetables from Jos-North and Jos-South LGAs. Hence, these vegetables are potential health hazards as the build-up of lead in the human system has deleterious consequences at the long run. The symptoms of acute lead poisoning are headache, irritability, abdominal pain and various symptoms related to the nervous system. Lead encephalopathy is characterized by sleeplessness and restlessness. Children may be affected by behavioural disturbances, learning and concentration difficulties. In severe cases of lead encephalopathy, the affected person may suffer from acute psychosis, confusion and reduced consciousness. People who have been exposed to lead for a long time may suffer from memory deterioration, prolonged reaction time and reduced ability to understand. Individuals with average blood lead levels under $3 \mu \mathrm{mol} / 1$ may show signs of peripheral nerve symptoms with reduced nerve conduction velocity and reduced dermal sensibility. If the neuropathy is severe the lesion may be permanent. The classical picture includes a dark blue lead sulphide line at the gingival margin. In less serious cases, the most obvious sign of lead poisoning is disturbance of haemoglobin synthesis, and longterm lead exposure may lead to anaemia [34].

From the foregoing, this study shows that Lettuce and spinach are very efficient bioaccumulators of all the metals sampled, which is in agreement with the work of Pasquini [35], who reported that in all the farms he sampled in Jos, lettuce contained very large concentrations of lead, cadmium and iron that were 20 to 40 times higher than the WHO/FAO maximum permissible limits in leafy vegetables for human consumption.

\section{Conclusion}

Heavy and trace metals show highly significant build-up in the vegetable samples from Jos-North and Jos-South LGAs. Barkin Ladi LGA has a lesser but significant levels of these metals in the vegetables sampled. Cadmium and lead were not detected in all the vegetables sampled from Bassa LGA; there is a lesser but significant build-up of the trace metals as compared to other LGAs. All the metals are present in all the vegetables from Barkin Ladi, but the level of contamination, though significant, is lower than those from JosNorth and Jos-South. The variation of these metals in the vegetables from these areas may be attributed to anthropogenic activities. This study also shows that Lettuce and spinach are very efficient bioaccumulators of all the metals sampled. The authors therefore strongly recommend that people living in these areas should not eat large quantities of lettuce and spinach, so as to avoid excessive accumulation of these metals in the body. Dietary intake of contaminated foods with heavy metals results in long-term low level bioaccumulation and the detrimental impact becomes apparent only after several years of exposure. Thus regular monitoring of these toxic heavy metals from Soil, effluents and sewage, in vegetables and in other food materials is essential, to prevent their excessive build-up in the food chain.

\section{References}

[1]. R. Singh, N. Gautam, A. Mishra and R. Gupta, Heavy metals and living systems: An overview, Indian J. Pharmacol. 43(3), 2011, $246-253$.

[2]. J. D. Dabak, S.Y. Gazuwa and G. A. Ubom, Comparative hepatotoxicity test of cadmium and lead in rats, Journal of Med in the Tropics 14, 2011, 12-18.

[3]. J. D. Dabak, S. Y. Gazuwa and G. A. Ubom, Hepathoprotective Potential of Calcium and Magnesium against Cadmium and Lead Induced Hepatotoxicity in Wister Rats, Asian J. of Biotech 1(1), 2009, 12-19.

[4]. J. D. Dabak, S. Y. Gazuwa and G. A. Ubom, Nephroprotective potential of calcium and magnesium against cadmium and lead nephrotoxicity in rats, Asian Journal of experimental Biological sciences 3(1), 2012, 214-221.

[5]. H. L. Ramesh and V. N. Y. Murthy, Assessment of Heavy Metal Contamination in Green Leafy Vegetables Grown in Bangalore Urban District of Karnataka, Advances in Life Science and Technology 16, 2012, 40-49. 
[6]. K. P. Singh, D. Mohan, S. Sinha, and R. Dalwani, Impact assessment of treated and untreated wastewater toxicants discharged by sewage treatment plants on health, agricultural, and environmental quality in the wastewater disposal area, Chemosphere 55, 2004, $227-255$.

[7]. H. M. Naser, N. U. Mahmud, S. Sultana, R. Gomes and M. Rahman, Trace elements content in vegetables grown in industrially polluted and non-polluted areas. Bangladesh J. Agril. Res. 37(3), 2012, 515-527.

[8]. M. Harmanescu, L. M. Alda, D. M. Bordean, I. Gogoasa and I. Gergen, Heavy metals health risk assessment for population via consumption of vegetables grown in old mining area; a case study: Banat County, Romania. Chemistry Central Journal 5, 2011, 6474.

[9]. A. Singh, R. K. Sharma, M. Agrawal and F.M. Marshall, "Risk assessment of heavy metal toxicity through contaminated vegetables from waste water irrigated area of Varanasi”, Indian Tropical Ecology, 51(2), 2010, 375-387.

[10]. J.D. Gyang and E. Ashano, The role of geosciences in sustainable development of an expanding urban region: A case study of the Jos-Bukuru urban region, north central Nigeria.

[11]. The Pacific Journal of Science and Technology 11(2), 2010, 644-670.

[12]. A. Haloi, C. R. Thabah, D.K. Limbu, P.S. Dkhar and Chakraborty, Assessment of certain elements in some common edibles from DandaraAgyathuri villages of Kamrup district of Assam. J. Hum. Ecol. 31(2), 2010, 79-85.

[13]. I. M. Skurikhin, Method Analysis for toxic Elements in Foods, Part IV, General method of ashing for the determination of toxic elements, Journal of AOAC International 7, 1993, 257- 262.

[14]. M. Arora, B. Kiran, S. Rani, A. Rani, B. Kaur and N. Mittal, Heavy metal accumulation in vegetables irrigated with water from different sources, Food Chemistry 111, 2008, 811-815.

[15]. A. Asdeo and S. Looker, A comparative analysis of trace metals in vegetables, Res. J. Envir. Toxicol. 5(2), 2011, 125-132.

[16]. M. J. Khan, M. T. Jan, F. Tullah, N. U. Khan, M. Arif, S. Perveen, S. Alam and A. U. Jan, The effect of using waste water for tomato, Pak.J. Bot. 43(2), 2011, 1033-1044.

[17]. J. Kim, K. Kim, J. U. Lee, J. S. Lee and J. Cook, Assessment of As and heavy metal contamination in the vicinity of Duckum AuAg mine, Korea, Environmental geochemistry and health 24, 2002, 215-227.

[18]. A. I. Tsafe, L. G. Hassan, D. M. Sahabi, Y. Alhassan and B. M. Bala, Evaluation of Heavy Metals Uptake and Risk Assessment of Vegetables Grown in Yargalma of Northern Nigeria. J. Basic. Appl. Sci. Res. 2(7), 2012, 6708-6714.

[19]. A. A. Audu and A. O.Lawal, Variation in metal contents of plants in vegetable garden sites in Kano Metropolis. J Appl Sci Environ Manage. 10, 2006, 105-109.

[20]. A. O. Lawal and A. A. Audu, Analysis of heavy metals found in vegetables from cultivated irrigated gardens in the Kano metropolis, Nigeria. J Environ Chem Ecotoxicol. 3(6), 2011, 142-148.

[21]. H. Lokeshwari and G.T. Chandrappa, Impact of heavy metal contamination of Bellandur lake on soil and cultivated vegetables, Curr. Sci. 91, 2006, 622-627.

[22]. H. L. Ramesh and V. N. Yogananda Murthy, Assessment of Heavy Metal Contamination in Green Leafy, Advances in Life Science and Technology, 16, 2012, 40-51.

[23]. Y. Chen, Y., Wang, C., and Z. Wang, Residues and source identification of persistent organic pollutants in farmland soils irrigated by effluents from biological treatment plants, Environment International 31, 2005, 778-783.

[24]. T. Chen, X. Liu, M. Zhu, K. Zhao, J. Wu, J. Xu and P. Huang, Identification of trace element sources and associated risk assessment in vegetable soils of the urban-rural transitional area of Hang Zhou, China, Environmental Pollution 151, 2008, 67-78.

[25]. M. Muchuweti, J. W. Birkett, E. Chinyanga, R. Zvauya, M. D. Scrimshaw, and J. N. Lester, Heavy metal content of vegetables irrigated with mixture of wastewater and sewage sludge in Zimbabwe: implications for human health, Agriculture, Ecosystem and Environment 112, 2006, 41-48.

[26]. Y. Kang, K. C. Cheung and M. H. Wong, Mutagenicity, genotoxicity and carcinogenic risk assessment of indoor dust from three major cities around the Pearl River Delta, Environment International 37(3), 2011, 637-643.

[27]. M. C. Navarro, C. Perez-Sirvent, M. J. Martinez-Sanchez, J. Vidal, P. J. Tovar and J. Bech, Abandoned mine sites as a source of contamination by heavy metals: A case study in semi-arid zone, Journal of Geochemical exploration 96, 2008, 183-193.

[28]. L. Jarup,M. Berglund, C. G. Elinder, G. Nordberg and M. Vahter, Health effects of cadmium exposure-a review of the literature anda risk estimate. Scand J Work Environ Health 24 (1), 1998, 1-51.

[29]. T. Alfven, C.G. Elinder, M.D. Carlsson, A. Grubb, L. Hellstrom and B. Persson, Low-level cadmium exposure and osteoporosis, J Bone Miner Res 15, 2000, 1579-1586.

[30]. G. Nordberg, T. Jin, A. Bernard, S. Fierens, J. P. Buchet, T. Ye, Q. Kong and H. Wang, Low bone density and renal dysfunction following environmental cadmium exposure in China, Ambio 6, 2002, 478-481.

[31]. E. C. Garcia, M. L. Cabrera, S. J. Lorenzo, C. and Lopez, "Daily dietary intake of chromium in Southern Spain measured with duplicate diet sampling" Br. J. Nutr. 86, 2001, 391-396.

[32]. S.,Adugna, L.A.M. Alemu, T.Kelemu, H.Tekola, B.Kibret, S.Genet, Lecture notes for health science students: Medical Biochemistry. Gondar University, Jimma University, Debub University; In collaboration with the Ethiopia Public Health Training Initiative, TheCarter Center, the Ethiopia Ministry of Health, and the Ethiopia Ministry of Education 2004, $185-185$.

[33]. J. A. LeClair and D. W Quig, Mineral status, toxic metal exposure and children's behavior, Journal of Orthomolecular Medicine 16(1), 2001, 13-32.

[34]. L. Jarup, Hazards of heavy metal contamination. British Medical Bulletin 68(1), 2003, 167-182.

[35]. M. W. Pasquini, The use of town refuse ash in urban agriculture around Jos, Nigeria: health and environmental risk, Science of the Total Environment 354(1), 2006, 43-59. 